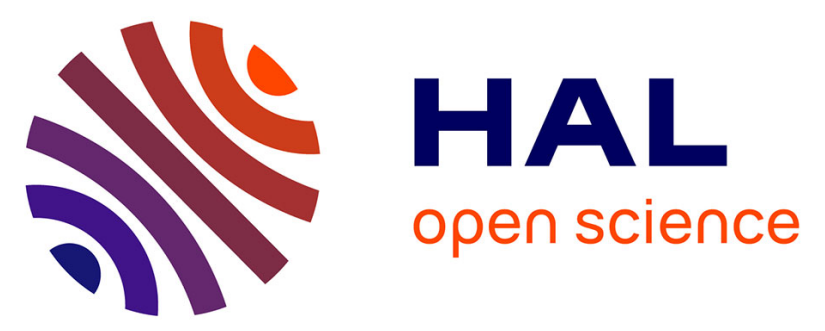

\title{
Atmospheric Pressure Deposition of Thin Functional Coatings: Polymer Surface Patterning by DBD and Post-Discharge Polymerization of Liquid Vinyl Monomer from Surface Radicals
}

Jean-Pascal Borra, Alexandre Valt, Farzi Arefi-Khonsari, Michael Tatoulian

\section{To cite this version:}

Jean-Pascal Borra, Alexandre Valt, Farzi Arefi-Khonsari, Michael Tatoulian. Atmospheric Pressure Deposition of Thin Functional Coatings: Polymer Surface Patterning by DBD and Post-Discharge Polymerization of Liquid Vinyl Monomer from Surface Radicals. Plasma Processes and Polymers, 2012, 9 (11-12), pp.1104-1115. 10.1002/ppap.201100210 . hal-03479653

\section{HAL Id: hal-03479653 https://hal.science/hal-03479653}

Submitted on 14 Dec 2021

HAL is a multi-disciplinary open access archive for the deposit and dissemination of scientific research documents, whether they are published or not. The documents may come from teaching and research institutions in France or abroad, or from public or private research centers.
L'archive ouverte pluridisciplinaire HAL, est destinée au dépôt et à la diffusion de documents scientifiques de niveau recherche, publiés ou non, émanant des établissements d'enseignement et de recherche français ou étrangers, des laboratoires publics ou privés. 
Plasma Process. Polym. 2012, DOI: 10.1002/ppap.201100210

Article Type: ((Feature article $))$

\title{
Atmospheric pressure deposition of thin functional coatings: polymer surface patterning by DBD and post-discharge polymerization of liquid vinyl monomer from surface radicals ${ }^{\mathrm{a}}$
}

\author{
J.-P. BORRA ${ }^{* 1,2,3}$, A. VALT ${ }^{4}$, F. AREFI-KHONSARI ${ }^{4}$, M. TATOULIAN ${ }^{4}$
}

${ }^{1}$ Université Paris-Sud, Laboratoire de Physique des Gaz et des Plasmas (UMR8578)- Equipe Décharges Electriques et Aérosols, Orsay, F-91405

${ }^{2}$ CNRS, Orsay, F-91405

${ }^{3}$ Supelec, 3 rue Joliot-Curie, Gif-sur-Yvette, F-91192

Fax: 00.33.1.69.85.17.99 ; E-mail: jp.borra@pgp.u-psud.fr

${ }^{4}$ Laboratoire de Génie des Procédés Plasmas et Traitements de Surface, Université paris 6Chimie-ParisTech, 11 rue Pierre et Marie Curie 75005 Paris- France

\section{Abstract.}

We present a route for grafting polyacid and polyether coatings on polymers by post-

discharge polymerization of liquid vinyl monomer. Surface modifications of polymer films by Micro-Discharges in air Dielectric Barrier Discharge (MD, DBD) are depicted with submicrometer craters homogeneously distributed. Both the energy per MD and the power density are critical to avoid thermal film deformation. Homogeneous surface composition is related to the DBD energy density.

The polymerization mechanism is depicted from yields versus DBD energy density and time of exposure to air between DBD and monomer deposition. Both parameters control the surface density of radicals and peroxides, triggering the post-DBD polymerization with 80 and $73 \%$ of monomer functionality remaining in acid and ether coatings, respectively.

The effect of deposition conditions on coatings properties is shown as well as the stability of coatings upon washing.

\footnotetext{
a $\square$ Supporting information for this article is available at the bottom of the article's abstract page, which can be accessed from the journal's homepage at http://www.macros.wiley-vch.de, or from the author. ((Other footnotes to the title/authors can also appear here, such as Author-One and Author-Two contributed equally to this work.))
} 


\section{1- Introduction}

Low-pressure glow discharges produce adherent thin coatings of a few tens of nanometers with different surface functionalities ${ }^{[1,2]}$. In that context, great efforts have been made to develop new processes for surface treatment or deposition in air at atmospheric pressure ${ }^{[3-11]}$. Badyal et al. have combined a droplet production device and an Atmospheric Pressure Glow Discharge in $\mathrm{He}$ and $\mathrm{N}_{2}$ to deposit poly-acid films ${ }^{[12]}$ and silicon-containing films ${ }^{[13]}$. The precursor was injected as liquid droplets into the Atmospheric Pressure Glow Discharge. Doing so, the deposition rate is not limited by the vapor pressure of the organic precursor and even nonvolatile precursors can be used. More recently, Herbert et al. ${ }^{[14]}$ directly compared vapor and liquid aerosol precursors for the deposition of perfluorocarbon coatings by atmospheric pressure non-thermal equilibrium plasma jet system to evaluate the monomer fragmentation in the plasma and the subsequent coating properties. While coatings deposited from liquid precursors showed good retention of monomer molecular structure, they exhibited poor stability when immersed in toluene. This was attributed to lower levels of cross-linking in coatings deposited in the plasma from liquid precursor than from gaseous precursors. This paper deals with the process developed to preserve the monomer functionality by postdischarge deposition and polymerization of liquid monomer at atmospheric pressure ${ }^{[15]}$. Indeed, as previously shown with highly functionalized poly-acid coatings, post-DBD Electro-Spray (ES) deposition is a promising method for polymerization of unsaturated precursors at atmospheric pressure: the DBD generates surface radicals and labile peroxides that will initiate the grafting polymerization of vinyl monomers and the interlocking of the coating with the substrate, while ES leads to high deposition rate of liquid monomer ${ }^{[6,7]}$. In this paper, the effects of filamentary air DBD, in which micro-discharges (MD) are homogenously distributed in time and space, on the surface of the polyethylene (PE) and polystyrene (PS) substrates are depicted through SEM, XPS and FTIR-ATR analysis. Then, the polymerization yield of poly-ether coatings has been defined by mass measurements 
carried out on PS substrates. The yield is shown to depend on the energy density deposited by DBD and on the time exposure to air before deposition. To account for the remaining monomer functionality in the polymerized coatings, we propose a mechanism of postdischarge polymerization of vinyl monomer induced by surface radicals and peroxides grafted by the preliminary DBD treatment. The effect of deposition conditions on coatings properties is shown as well as stability of coatings upon washing.

\section{2- Experimental Part}

\section{1- Set-up}

The post discharge polymerization of the vinyl precursor is a two step process (Figure 1).

\section{Plasma activation}

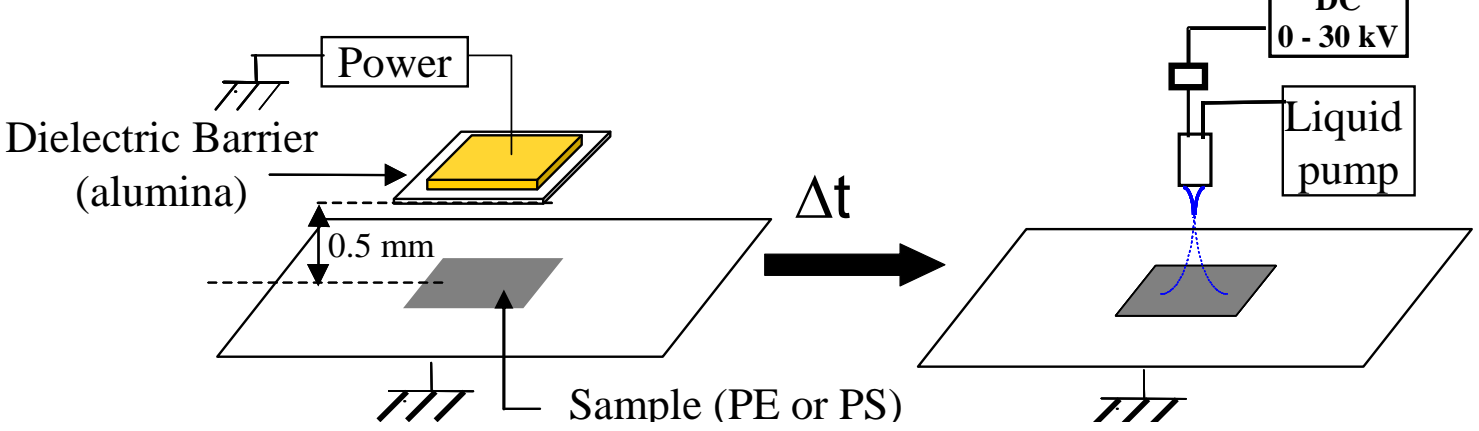

Figure 1: Schematic of set-up for DBD activation of the polymer film and for ES deposition The polymer substrate is first activated by a $0.5 \mathrm{~mm}$ gap plane-to-plane Dielectric Barrier Discharge ( $4 \times 2 \mathrm{~cm}$ covered by a $0.5 \mathrm{~mm}$ thick alumina) in air at atmospheric pressure to achieve more homogeneous surface activation than in longer gaps, as detailed in $\S 3.1$. The polyethylene and polystyrene films with respectively 0.1 and $0.125 \mathrm{~mm}$ thickness $(5 \times 5 \mathrm{~cm})$ are placed on a grounded electrode, translated under the 30 or $45 \mathrm{kHz}$ DBD with velocities from 0.1 to $4.5 \mathrm{~cm} / \mathrm{s}$. The power density $\left(\mathrm{Ps}\right.$ in $\mathrm{W} / \mathrm{cm}^{2}$ ) is defined as the mean input power divided by the treated surface of the film. The mean power is calculated as the integral of the (u.i.dt) product over an integer number of voltage periods divided by the integration duration. The Energy density (Es in $\mathrm{J} / \mathrm{cm}^{2}$ ) has been calculated by two methods: as the power density integral over the treatment duration, or as the product of the energy per pulse related to single 
micro-discharge, of the number of pulses per time and space units and of the treatment duration, as derived from a numerical treatment of the discharge currents, ${ }^{[16,17]}$. The power density is controlled by tuning the energy density with voltage, gap length and specific capacitance of the dielectric material at a fixed transit time in the discharge, or conversely. Results are discussed in terms of power density to deal with the dynamic of substrate heating by DBD and cooling by heat exchanges to define the range of power density preventing the thermal deformation of the polymer. On the contrary, to account for the final surface density of species triggering the post-discharge polymerization, the energy density is used to compare chemical effects of different DBD pre-treatments of the polymer substrate.

Then, the deposition of the liquid precursor is performed by Electro-Hydro Dynamic Atomization, also called Electro-spray (ES) in cone-jet mode. The Di-Ethyl-Glycol MonoVinyl Ether monomer (DEGMVE 98\%) is so-deposited at constant distance between the substrate and the spraying nozzle, defining the deposition spot diameter on the substrate. The mass deposited per surface unit was tuned by performing either several passages under the spray at $0.5 \mathrm{~mL} / \mathrm{h}$ or one passage at different liquid flow-rates, both at constant substrate velocity, as well as by changing the substrate velocity at constant flow rate.

After deposition of the liquid precursor, samples are stored at ambient pressure and temperature for $25 \mathrm{~h}$ polymerization before evaporation of residual liquid monomer (at $40 \mathrm{mbar}$ and room temperature) and final mass measurement. This maximal duration of polymerization has been defined for the thickest polymerized coatings, by showing that the final mass of coating does not evolve with longer polymerization duration between deposition and evaporation. However, faster polymerization with related shorter duration in the order of one hour has been recorded for thinner polymerized coating in ambient conditions. For industrial purposes, the polymerization can be shortened by tuning the kinetics of polymerization of thinner coatings with temperature, eventually accelerated by UV irradiation for volume polymerization and/or evaporated faster by heating at reduced pressures. 


\section{2- Substrate and coating characterization}

Chemical surface analyses were performed on different parts of the sample. At least three lines with nine spots per line perpendicular to the displacement direction, were analyzed with deviations smaller than $5 \%$ compared to the mean value. To analyze the surface composition, XPS spectra were recorded using an X-Ray Photoelectron Spectrometer (XPS - PHI 5600-ci spectrometer - Physical Electronics) without charge compensation. Survey and high resolution spectra were acquired at a detection angle of $45^{\circ}$, using the $\mathrm{K} \alpha$ line of a standard (non-monochromatized) $\mathrm{Al}(\mathrm{h} v=1486.6 \mathrm{eV})$ and $\mathrm{Mg}(\mathrm{h} v=1253.6 \mathrm{eV}) \mathrm{X}$-ray sources respectively, operated at $300 \mathrm{~W}$. The photoelectrons take-off angle was $45^{\circ} / n$, and the analyzed surface evaluated at $0.8 \times 0.8 \mathrm{~mm}^{2}$. The curve fitting for the high resolution $\mathrm{C}_{1 \mathrm{~s}}$ core level peaks was determined using XPS PEAK (Version 4.1) with a Lorentz-Gauss ratio of 5 (0: G, 100: L) and a Shirley background subtraction for high resolution C1s spectra. The energy resolution of the survey and the high resolution spectra were approximately $2 \mathrm{eV}$ and $0.8 \mathrm{eV}$, respectively. The peak positions were determined with an accuracy of $0.2 \mathrm{eV}$ with widths of $1.5 \mathrm{eV}$ for $\mathrm{C} 1 \mathrm{~s}$ and $1.6 \mathrm{eV}$ for N1s.

The quantitative analysis of the surface composition was estimated from the integrated peak areas normalized by the relative sensitivity Scofield factors ${ }^{[18]}$, the electron mean free path, and the apparatus transmission function. The relative sensitivity factors depending on the nature of the element were 1.00 and 1.77 for $\mathrm{C} 1 \mathrm{~s}$, and $\mathrm{N} 1 \mathrm{~s}$, respectively.

FTIR-ATR spectra were obtained with a germanium crystal (MIRacle ${ }^{\text {TM }}$-ATR, BRUKER). The final mass of the polymerized coating was defined on three samples, by mass difference between the initial and coated samples after evaporation of residual monomer (with $5 \%$ error from $10 \mu \mathrm{g}$ to a few $\mathrm{mg}$ ). The polymerization yield was calculated as the ratio of the final mass of polymer coating by the initial mass of deposited liquid monomer. Finally, SEM has been used to characterize the surface topography and side views to measure the coating thickness. 


\section{3- Results and Discussion}

\section{1- Chemical and structural effects of filamentary DBD on polymer film surface}

The expected effects of plasma treatment of polymer surfaces in air at atmospheric pressure ${ }^{[19]}$ are confirmed. Indeed, a decrease in the contact angle and an increase in the oxygen content was measured for both PE and PS films for energy densities higher than $2 \mathrm{~J} / \mathrm{cm}^{2}$, as depicted in Figure 2 and related table 1 for PS; It has to be noticed that the surface composition has been shown to be constant at different locations on the polymer film substrate treated by DBD, with deviation smaller than $5 \%$ with respect to the mean values in table 1, as detailed in $§ 2.2$ and shown on XPS spectra in Figure 2 and 4 for PS, below.

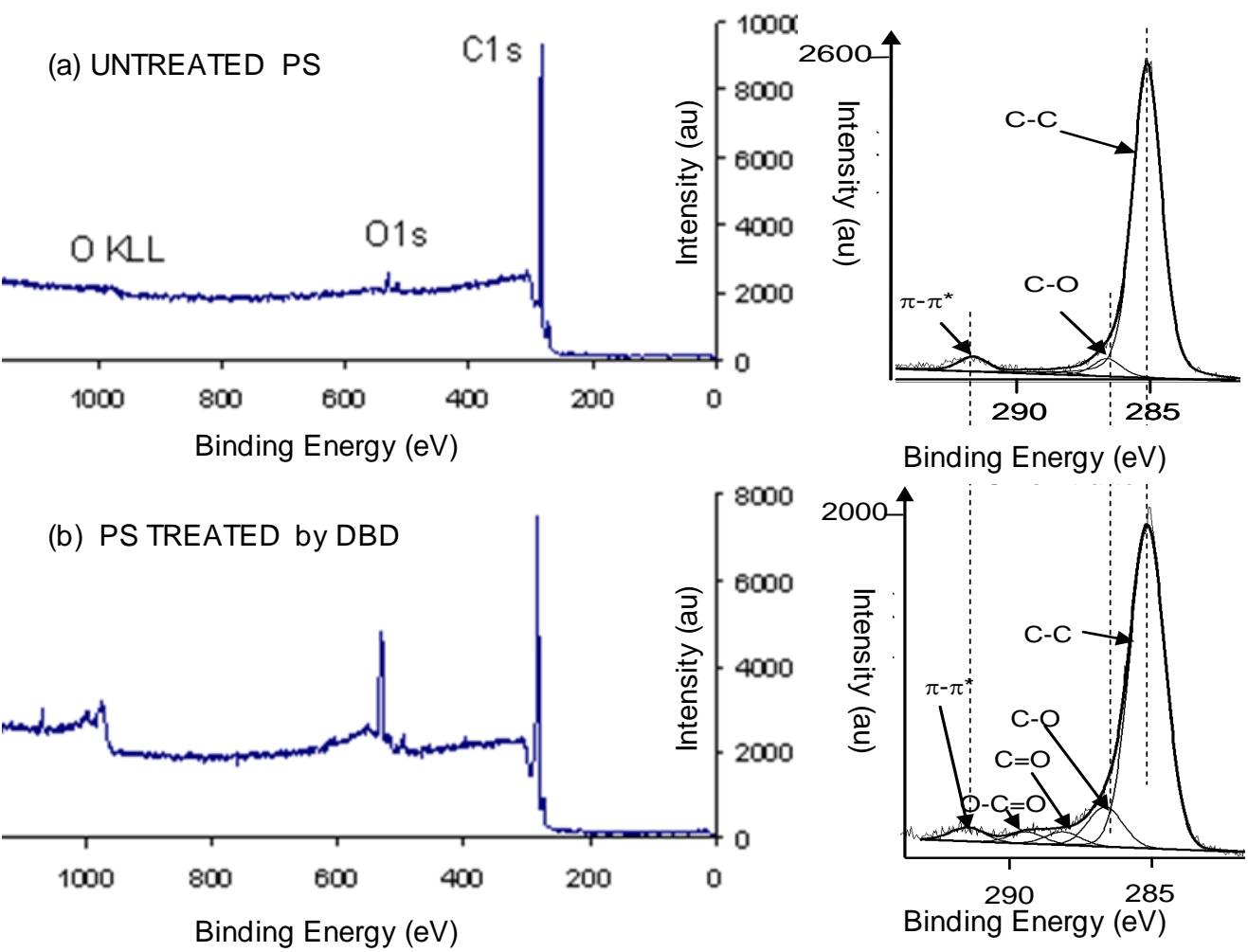

Figure 2: low resolution and high resolution C1s XPS spectra of (a) non treated PS and (b) $P S$ film treated by $D B D\left(E s=4 J / \mathrm{cm}^{2}, f=45 \mathrm{kHz}, v=4.3 \mathrm{~mm} / \mathrm{s}\right)$.

Nitrogen at the topmost surface layer can also be noticed from the low resolution XPS spectra (around $400 \mathrm{eV}$ ) for treated PS presented on Figure 2, representing less than $2 \%$ of the atomic surface composition, far below Oxygen. It highlights the higher reactivity of oxygen than of nitrogen with PS surface in the discharge used for the DBD pre-treatment in air. Moreover, 
the high concentration of oxygen after DBD treatment could be due to post-oxidative reactions.

Table 1: XPS analysis of PS before and after DBD treatment, showing the evolution of the $C 1 s$ core level peak decomposition into five features(expressed in \%, as the ratio of the area for each Carbon bond over the total area of the Cls peak) and the Oxygen to Carbon ratio

\begin{tabular}{|c|c|c|c|c|c|}
\hline & \multirow{3}{*}{$\begin{array}{c}\text { Untreated } \\
\text { reference } \\
\text { PS }\end{array}$} & \multicolumn{4}{|c|}{ Post-DBD treatment } \\
\hline & & \multicolumn{3}{|c|}{$14 \mathrm{kV}$} & \multirow{2}{*}{$\begin{array}{c}16 \mathrm{kV} \\
4.3 \mathrm{~mm} / \mathrm{s} \\
60 \mathrm{~J} / \mathrm{cm}^{2} \\
\end{array}$} \\
\hline & & $\begin{array}{c}4.3 \mathrm{~mm} / \mathrm{s} \\
4 \mathrm{~J} \mathrm{~cm}^{2}\end{array}$ & $\begin{array}{l}3 \mathrm{~mm} / \mathrm{s} \\
6 \mathrm{~J} / \mathrm{cm}^{2}\end{array}$ & $\begin{array}{c}1 \mathrm{~mm} / \mathrm{s} \\
17 \mathrm{~J} / \mathrm{cm}^{2}\end{array}$ & \\
\hline$\% \mathrm{C}-\mathrm{C}(285 \mathrm{eV})$ & 89.5 & 83.2 & 83.8 & 82.4 & 77.0 \\
\hline \% C-O-C (286.5 eV) & 5.1 & 8.7 & 9.1 & 8.8 & 11.5 \\
\hline$\% \mathrm{C}=\mathrm{O}(288 \mathrm{eV})$ & 0.7 & 2.5 & 2.3 & 2.8 & 4.3 \\
\hline$\% \mathrm{O}-\mathrm{C}=\mathrm{O}(289.3 \mathrm{eV})$ & 0.6 & 2.3 & 2.0 & 2.8 & 3.7 \\
\hline$\% \pi-\pi^{*}(291.5 \mathrm{eV})$ & 4.1 & 3.3 & 2.8 & 3.2 & 3.5 \\
\hline $\mathrm{O} / \mathrm{C}$ & 0.058 & 0.144 & 0.155 & 0.17 & 0.209 \\
\hline
\end{tabular}

The Oxygen to Carbon ratio is the ratio of the atomic percentages of Oxygen and Carbon in the surface composition derived from low resolution XPS spectra. It lies around 0.058 for the reference untreated PS, arising from additives or impurities. New $\mathrm{CO}$ bonds $(\mathrm{C}=\mathrm{O}$ at $288 \mathrm{eV}$, $\mathrm{O}-\mathrm{C}=\mathrm{O} 189.3 \mathrm{eV}$ ) result from $\mathrm{DBD}$ in air increasing the $\%$ of $\mathrm{CO}$ bonds, initially present in the non-treated PS and the Oxygen to Carbon ratio.

To achieve stable discharges with homogeneously distributed micro-discharges during the surface treatment in air DBD without burning or breaking through the substrate, the energy per MD has to be lower than $1 \mu \mathrm{J}$. This implies discharge gaps shorter than $1 \mathrm{~mm}$. Moreover, power densities have to be smaller than 1.7 and $2.3 \mathrm{~W} / \mathrm{m}^{2}$ respectively for PE and PS, with slightly lower power density for longer treatments. Indeed, polymers are thermal insulator materials, reaching higher surface temperature at slower substrate velocities due to heat accumulation from poor heat conduction and related cooling rate. Hence, this maximum power density is related to the softening temperature specific of each polymer film, easily reached in 30 to $60 \mathrm{kHz} \mathrm{DBD}^{[20]}$. Indeed, the surface is heated up to macro-scale deformation of the film and subsequent discharge destabilization arising from the gap length modification. 
SEM pictures of PE films treated by DBD (cf. Figure 3a) reveal 100 to $200 \mathrm{~nm}$ craters homogeneously distributed over the surface every 200 to $500 \mathrm{~nm}$ with $0.5 \mathrm{~mm}$ gap and 200 to $400 \mathrm{~nm}$ craters every 400 to $800 \mathrm{~nm}$ with $1 \mathrm{~mm}$ gap. Both craters diameter and density can be respectively related to the energy per MD and to the surface density of micro-discharges. Indeed, the energy is twice higher and the surface density of micro-discharges is twice smaller at $1 \mathrm{~mm}$ than at $0.5 \mathrm{~mm}$ for a constant power density.

For PS, the DBD treatment produces nano-thick delaminated slices of oxidized PS fragments, as discussed in §-3.2 Post-discharge polymerization yield and mechanism (cf. Figure 3b).
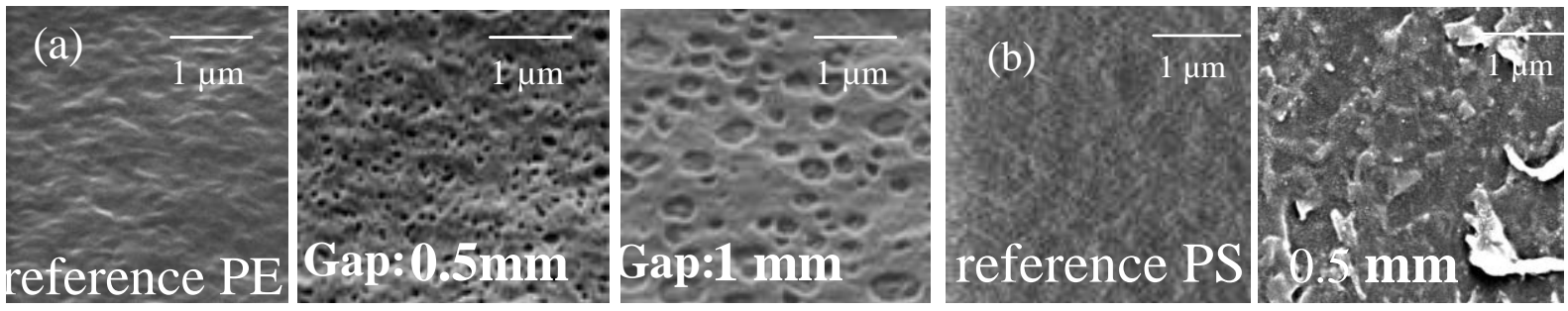

Figure 3: (a) untreated / treated PE by DBD for 0.5 and $1 \mathrm{~mm}$ gap lengths and (b) untreated / treated PS by $0.5 \mathrm{~mm} \mathrm{DBD}$

The erosion of polymer surfaces was expected since the production of vapors and nanoparticles by interaction of micro-discharges in filamentary DBD with metal and metal oxide surfaces is known ${ }^{[21,22]}$. However, the quasi-homogeneous distribution of such craters, much smaller than the 10 to $100 \mu \mathrm{m}$ MD diameter and much closer than the mean inter-MD distance in the order of the gap length (Figure 3a), still deserves to be clarified. This may be due to faster depolarization of polymer than of Alumina, leading to successive MD at the same places on the alumina and at different places on the substrate. Hence, homogeneous surface properties at a millimeter scale (spot diameter of IR and XPS analysis) can be achieved by air DBD, despite local heterogeneity of the MD interaction with the surface.

\section{2- Post-discharge polymerization yield and mechanism.}

\subsection{1- Preserved functionalities of the monomers in the polymerized coatings}


The monomer functionality is preserved in polymerized coatings. Up to $80 \%$ of monomer functionality remains in poly-acid coatings ${ }^{[6,7]}$ as confirmed here for poly-ether coatings by surface and bulk analysis.

The Figure 4a indicates a decrease of the $\mathrm{C}-\mathrm{C}$ peak at $285.0 \mathrm{eV}(\mathrm{C}-\mathrm{C} / \mathrm{C} 1 \mathrm{~s}$ ratio vary from 80 in the PS treated by DBD to $22 \%$ in the polyether coating) and an increase of the C-O peak at $286.5 \mathrm{eV}$ for ether and alcohol functions $(\mathrm{C}-\mathrm{O} / \mathrm{C} 1 \mathrm{~s}$ ratio vary from 10 to $61 \%)$. The disappearance of the $\pi-\pi *$ peak at $291.5 \mathrm{eV}$ for the poly-ether coating (Figure 4.b), corresponding to the phenyl carbons of the PS, indicates that the coating is thicker than the 5$10 \mathrm{~nm}$ depth of XPS analysis and that a homogeneous polymerized coating has been formed on the substrate, without any pore. Figure $4 \mathrm{~b}$ shows that the ether functionality of the monomer is preserved in the polymerized coating. Up to $73 \%$ of the $\mathrm{C}-\mathrm{O}$ functions of the monomer remain in the final polymerized coating. This is deduced by comparing the C-O/ $\mathrm{C} 1 \mathrm{~s}$ ratio in the poly-ether coating and in the monomer $\left(\mathrm{CH}_{2}=\mathrm{CH}-\mathrm{O}-\mathrm{CH}_{2}-\mathrm{CH}_{2}-\mathrm{O}-\mathrm{CH}_{2}-\mathrm{CH}_{2}-\right.$ $\mathrm{OH}$ with $5 \mathrm{C}-\mathrm{O}$ bonds for 6 Carbon atoms, i.e. $83.3 \%$ ).

Hence, the post-discharge deposition of the liquid monomer is proved to be an efficient strategy to preserve the monomer functionality by triggering the polymerization of vinyl monomers from surface radical, previously created on the substrate by DBD. 


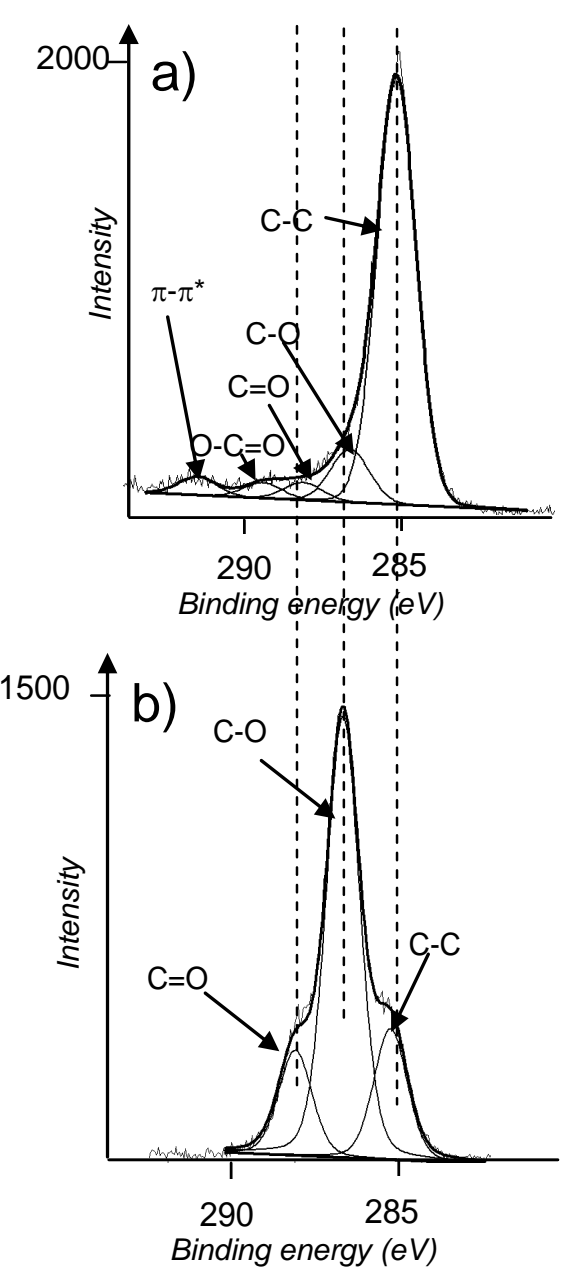

Figure 4: high resolution C1s XPS spectra of (a) PS treated by DBD (9.3 J.cm-2 at $0.5 \mathrm{~mm})$ and $(b)$ poly-ether coating on PS treated by DBD ( $\triangle t$ DBD-ES deposition $=23 \mathrm{~s}$ and $m s=62.5$ $\left.\mu \mathrm{g} / \mathrm{cm}^{2}\right)$.

However, as XPS cannot differentiate alcohol from ether functions, FTIR-ATR has been used to prove the retention of the ether groups in the polymerized coating. Indeed, Figure 5 reveals ether functions at 1066 and $1126 \mathrm{~cm}^{-1}$ and alcohol functions around $3400 \mathrm{~cm}^{-1}$. 

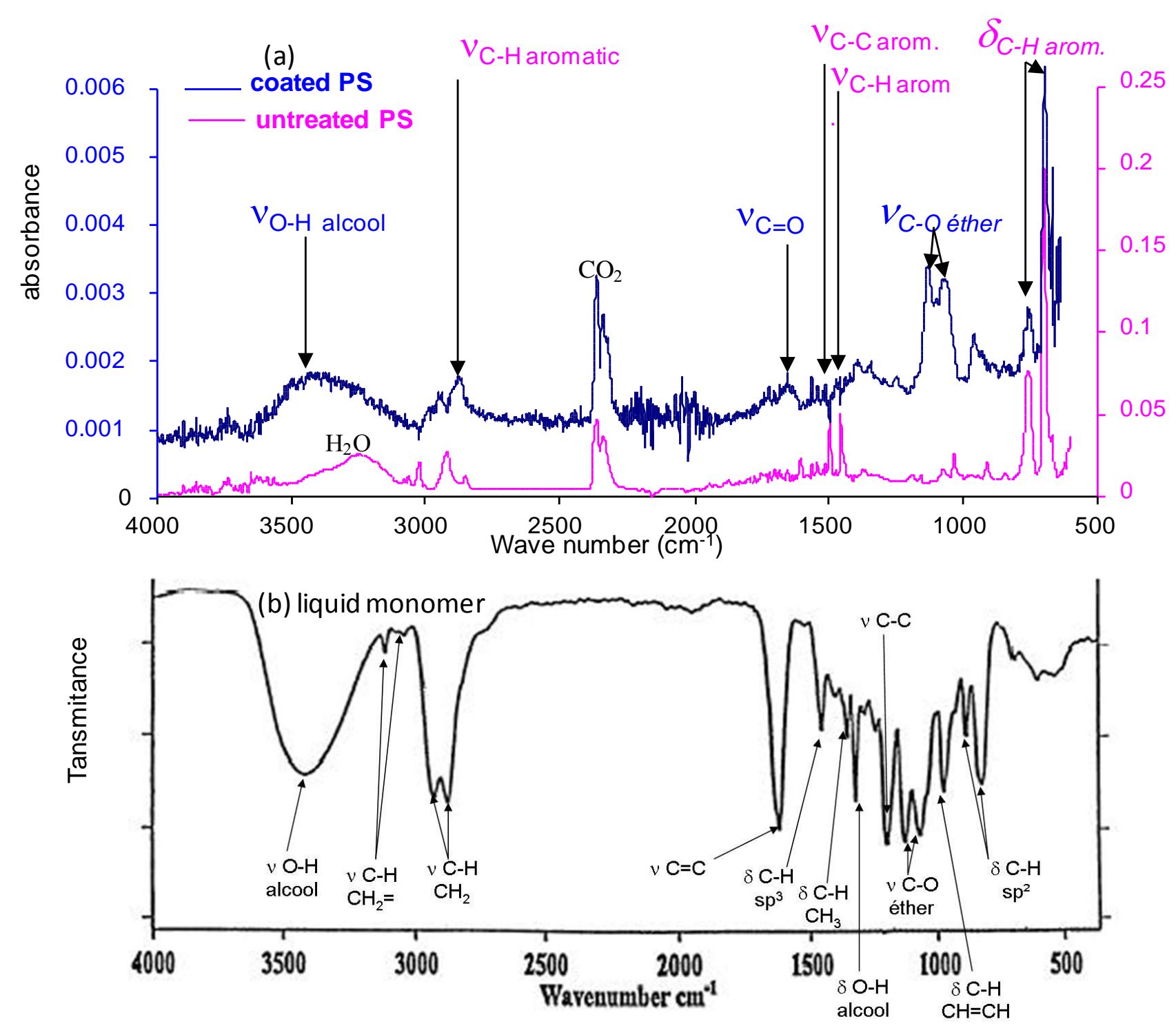

Figure 5: FTIR-ATR spectra (a) of untreated PS and polyether coating on PS from which the untreated PS spectra has been subtracted (coated PS) and (b) of the liquid monomer

From FTIR-ATR spectra of poly-ether coatings, some aromatic C-C and C-H bonds from the PS substrate or from additives are still detected in the bulk of 10 to $20 \mu \mathrm{m}$ coatings, measured as detailed in $\S 2.2$ and 3.3.1. A test experiment has been performed with HPLC analysis of the liquid monomer deposited on the PS substrate after DBD treatment. Our results indicate that low molecular fragments containing aromatic moieties are still present at the topmost surface layer of the PS. Such contaminants could be due to the presence of UV absorbers, mono-phenol absorbers, generally used as stabilizers retarding yellowing ${ }^{[23]}$. Besides, they can also arise from the DBD pre-treatment in air producing delaminated slices of oxidized PS, as 
confirmed by the carbonyl bond detected by FTIR in the polymerized coating on figure 5a. Comparing the final polymer coating and the liquid monomer spectra in figure $5 \mathrm{a}$ and $\mathrm{b}$, indicates a strong attenuation of the initial $\mathrm{C}=\mathrm{C}$ function at $1620 \mathrm{~cm}^{-1}$. Hence, the grafting polymerization occurs through the vinyl function. This confirms that post-discharge polymerization is triggered by surface reactions of the vinyl function of the monomer with species previously grafted on the substrate by DBD as detailed just below, which accounts for the resistance to washing discussed in section 3.3.2 by covalent interlocking of the coating with the substrate.

\subsection{2- Initiation of Polymerization of Vinyl Precursors from surface radicals}

Figures 6 show that the polymerization yield of polyether coatings on PS depends on the deposited energy density and on the time exposure to air between the substrate activation by DBD and monomer deposition. The energy density per surface unit was tuned by varying the substrate velocity and the related transit time of the substrate under the discharge at constant power density. The mass deposited per surface unit was modified as depicted in $\S 2.1$.

Figure 6a shows that the polymerization yield increases for energy density up to $2 \mathrm{~J} / \mathrm{cm}^{2}$. At constant mass of deposited liquid monomer, this implies higher final mass of polymerized coatings for higher energy density. This result supports that active species grafted on polymer substrates by DBD trigger the post-discharge polymerization. Indeed, the energy density deposited by the DBD pre-treatment has been shown to control the wettability ${ }^{[6,7]}$, the oxygen content of the surface (see table 1) which both have been related to the immediate post-discharge densities of surface radicals and peroxides ${ }^{[24-30]}$.

For DBD energy densities higher than $2 \mathrm{~J} / \mathrm{cm}^{2}$, the polymerization yield remains constant, probably due to a maximal surface density of radicals limited by self-recombination ${ }^{[24-30]}$. 

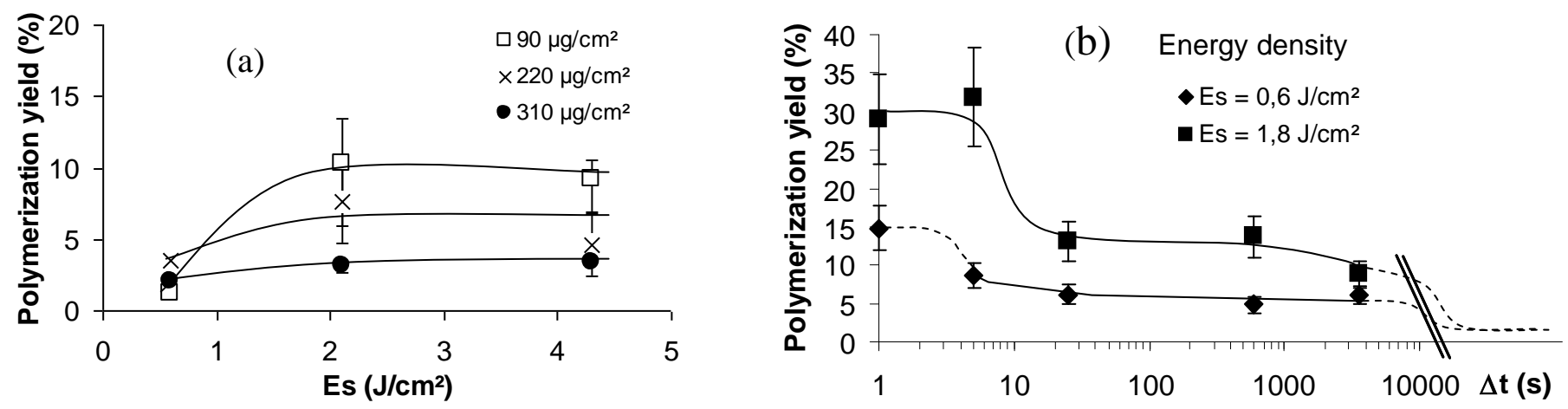

Figure 6 : Evolutions of polymerization yield of poly-ether coatings on PS versus (a) energy density for different mass of monomer deposited per surface unit and $(b)$ time exposure to air between DBD and ES deposition ( $\left.\mathrm{ms}=95 \mu \mathrm{g} / \mathrm{cm}^{2}\right)$

Then, kinetics of surface radicals recombination with oxygen prior to monomer deposition can be depicted from yield measurements related to the surface densities of active species triggering the polymerization of vinyl monomer. Indeed, the recombination of surface radicals with oxygen leads to peroxides and hydro-peroxides that can still trigger polymerization despite longer exposure to air before deposition. In the first experiment with acrylic acid, the transit time from DBD treatment to ES deposition was longer than a few seconds and is here reduced down to $1 \mathrm{~s}$. In this configuration, we can now depict the recombination kinetics of surface radicals, and/or post-oxidative reactions with air before liquid monomer deposition, which reduces the surface density of radicals as described with poly-acid formed on PE from surface peroxides ${ }^{[6,7]}$.

Figure $6 \mathbf{b}$ shows a three steps decrease of the polymerization yield versus the time exposure to air before deposition for different energy densities. For exposure to air shorter than few seconds, the polymerization yields are maximal, which tend to support that the initiation of polymerization is favored by high density of short life-time species such as radicals. Indeed, the post-discharge radical density is maximal but rapidly decreases with time by selfrecombination and reaction with oxygen to create more stable species such as peroxide and hydro-peroxides ${ }^{[21,22,24,26-28]}$, which directly affects the polymerization yield. Indeed, Figure 6b shows that the time of life of so-produced surface radicals by DBD pre-treatment of the substrate is smaller than 10s in air at Standard Temperature and Pressure (STP). 
However, the intermediate plateau of polymerization yields probably arises from a delayed formation of surface radicals, up to 600s in air at STP after the DBD surface activation step (cf. Figure 6b). This can arise from the formation of peroxide and hydro-peroxide which can lead through spontaneous dissociation of peroxide bonds to the delayed production of radicals to trigger a postponed polymerization, from 10 to $600 \mathrm{~s}$.

Then, above 600 s, the spontaneous polymerization of the monomer (called homopolymerization in volume) without any active species from the growing polymer chains leads to unadherent polymer without covalent binding to the substrate, as discussed below from resistance to washing, with $2-3 \%$ polymerization yields.

These data indicate that radicals are probably consumed in the first seconds of exposure to air. Beside, these results shows that grafted peroxides and hydro-peroxides on the surface of the polymer substrate treated by DBD also lead to a delayed production of radicals (e.g. with peroxide decomposition leading to oxygen radicals). Indeed, the polymerization from the surface is still triggered until 600 s after the pre-treatment. Hence, to increase the polymerization yield, the delay between DBD treatment and ES deposition must be the shortest to take advantage of higher initial radical densities. Finally, for air exposure before deposition longer than one hour, the yield decreases to a few \%, probably due to homopolymerization in volume forming non-adherent polymer.

\subsection{3- Termination of polymerization}

Figure 7 presents the final mass of poly-ether coating versus the deposited mass per surface unit of PS $\left(\mathrm{m}_{\mathrm{s}}\right.$ in $\left.\mu \mathrm{g} / \mathrm{cm}^{2}\right)$. In the case of poly-acid coating on PE, similar trends are observed, whatever the energy density of DBD pre-treatment of the substrate is.

Whatever the energy density deposited by DBD is, there is two ranges of deposited mass of liquid monomer leading to different mass of polymerized coatings. 


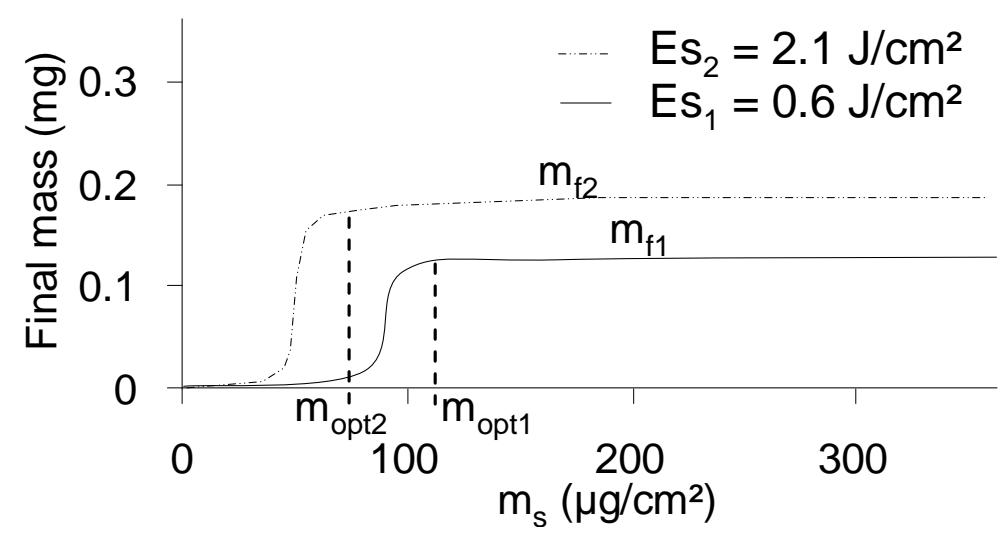

Figure 7: Evolution of the final mass of $4 * 5 \mathrm{~cm}$ polymerized coating versus the mass of liquid precursor deposited per surface unit for different energy densities.

For the lowest deposited mass of monomer per surface unit, isolated polymer dots were observed by SEM. Indeed, below $100 \mu \mathrm{g} / \mathrm{cm}^{2}$, there is not enough deposited liquid monomer to form a liquid film on the substrate and only individual droplets with diameter from 3 to 10 $\mu \mathrm{m}$ depending on liquid flow-rate, are deposited and polymerized. Since the evaporation rate increases for decreasing radius of curvature of the liquid surface, individual droplets evaporates faster than a liquid film. Hence, subsequent lower final mass of polymerized coatings and related yields arise from the polymerization of isolated droplets than from the polymerization of a liquid film, only observed for higher mass of deposited liquid monomer. As a result of isolated droplet polymerization, isolated dots made of agglomerates of nanometer polymerized grains are observed by SEM analysis (not shown here).

For higher deposited mass of monomer per surface unit, the final mass of polymerized coating does not evolve anymore with additional mass of deposited monomer per unit surface. Hence, the polymerization of a liquid film leads to a constant final mass of grafted polymer in relation to an excess of monomer that never polymerizes for both energy densities and related densities of active species. This supports the spontaneous termination of polymerization for a chain length depending on the volume density of radicals on growing polymer chains. On the plateau, this volume density of radicals appears to be the limiting parameter since the amount of monomer can increase without polymerizing. This suggests that the volume density of 
radicals on growing polymer chains depends on the energy density of the DBD pre-treatment, as confirmed in Figure 7 and discussed below for different energy densities.

Finally, for each energy density deposited by DBD, there is a corresponding maximal yield of polymerization for the optimal mass of deposited monomer, defined as the lower deposited mass of liquid monomer producing the maximal final mass of polymerized coating (from 0.14 to $0.18 \mathrm{mg}$ ). The optimal deposited mass of liquid decreases from 120 to $75 \mu \mathrm{g} / \mathrm{cm}^{2}$, for energy densities from 0.6 to $2.1 \mathrm{~J} / \mathrm{cm}^{2}$. This can be attributed to the reduction of the mass of polar liquid monomer required for the formation of a liquid film on more wettable polymer film substrates for higher energy densities. Besides, for higher deposited mass of monomer per surface unit than this optimal value, the final mass of polymerized coating varies with the energy density of the DBD pre-treatment. This confirms that the energy density of the DBD pre-treatment probably controls the initial surface density of actives species triggering the surface initiation of polymerization and the volume density of radicals required to extend the growing polymer chains.

\section{3- Coating properties versus ES deposition conditions.}

The production of monomer droplets is achieved by ES in the so-called «cone-jet » for the mono-dispersion of the droplet size distribution and for the stable conditions of deposition ${ }^{[31 \text {, }}$ ${ }^{32]}$. The ES produces unipolar charged micrometer droplets, which prevents coalescence and promotes fast electro-collection, limiting evaporation during the transit to the substrate ${ }^{[33]}$.

\subsection{1- Roughness, density and thickness of coatings.}

After deposition and polymerization of acid and ether vinyl monomers, the initial surface roughness of the substrates decreases. The presence of a dense polymer (no pores) is confirmed by the side view of polyacid and polyether coatings, presented on Figure 8. 

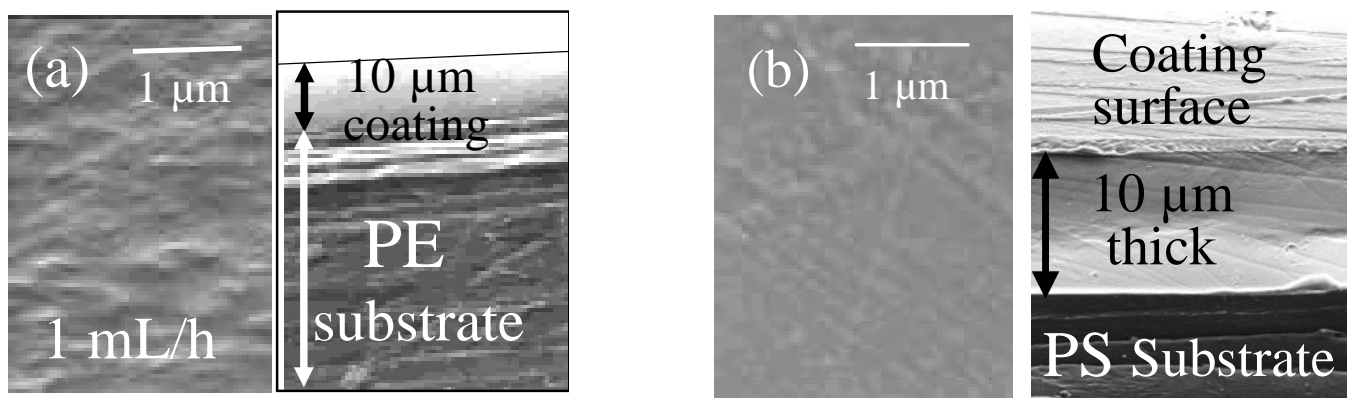

Figure 8: SEM pictures of (a) poly-acid deposited on PE at $1 \mathrm{~mL} / \mathrm{h}$ upper and side views; (b) poly-ether deposited on PS at $0.5 \mathrm{~mL} / \mathrm{h}$ upper and side views

With poly-acid and poly ether-coatings, the surface roughness decreases, due to thicker coatings at higher mass deposited per surface unit. Significant deposition rates of a few hundred nanometers per second are achieved for the liquid monomer, with final rate of polymerization of $0.1 \mathrm{~nm}$ per second at STP, that can be increased up to 1 to $10 \mathrm{~nm}$ per seconds, as detailed in $\S 2.1$.

As mentioned above, for each energy density of the DBD pre-treatment, there is a maximal yield of polymerization corresponding to a maximal thickness up to few tens of micrometers. Below this optimal mass deposited per unit surface, thinner coatings can be processed, since the thickness can be tuned with the mass deposited per surface unit either with flow rate, deposition duration and distance between the spraying nozzle and the substrate. Besides, for very small deposited mass per surface unit, individual drops can be deposited for surface processing with particular shapes of agglomerated polymer grains formed by polymerization within each drop. This can be of interest to increase the specific exchange surface for sensors. With both acid and ether vinyl precursors, the radial profiles of coating thickness have been defined by SEM side views and confirmed by radial profiles of surface ATR-IR absorbance of the carbonyl for the poly-acids coatings and of the ether for the poly-ether coatings.

On the other hand, the resulting coatings are thicker in the axis of the ES in relation with the higher droplet flux in the axis of the axi-symmetrical conical spray than on the edges (cf.

\section{Figure 9).}




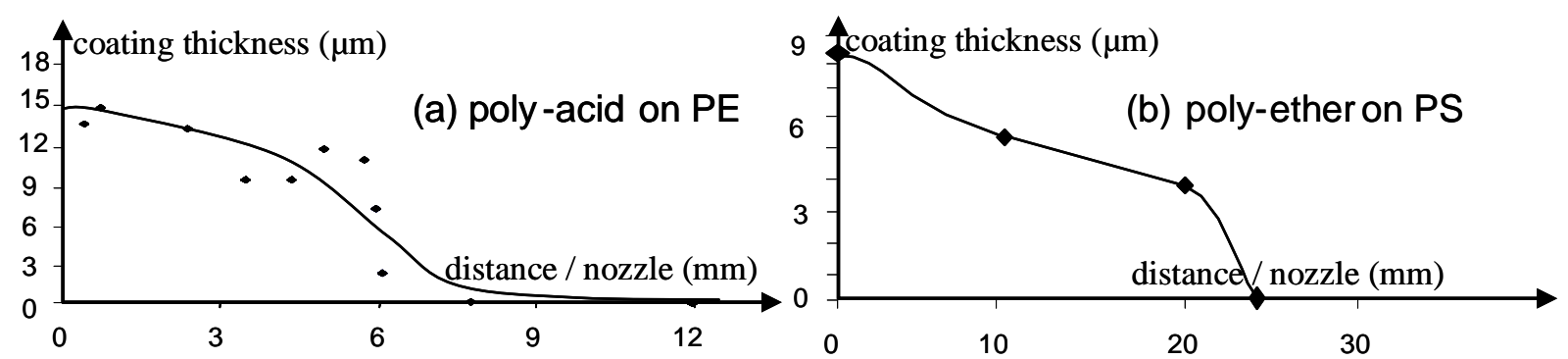

Figure 9: Thickness profiles from the spray axis of (a) poly-acid and (b) poly-ether coatings

This result is quite unexpected, because it demonstrates that the initial radial gradient of deposition flux of droplets is not totally flattened during the liquid film polymerization, which lasts here for hours. This can be used for structural surface processing with parallel channels formed with one line of multi-ES nozzles perpendicular to the displacement direction of the substrate or prevented by the use of a few lines of multi-ES nozzles with spraying heads position shifted from one line to another leading to flat surfaces on scrolling substrates. Besides, if related to higher electric field in the spray axis during deposition for a few seconds, this could be used to produce micro-functional pillars on static film by static fieldenhanced post-discharge polymerization.

\subsubsection{Resistance to washing.}

Resistance to washing is critical to account for the adhesion on the surface related to covalent binding to the substrate as well as for the cohesion related to cross-linking in the volume of the polymerized coating. For poly-acid coatings, XPS analyses have shown their resistance to severe washing conditions (soxhlet in ethanol, ${ }^{[6,7]}$ ) with a decrease of $10 \%$ of the carbonyl content when grafted on PE pre-treated by DBD. However, a complete loss of the poly-acid coating is induced by the same severe soxhlet extractions, when polymerized on non-treated PE film. Hence, the DBD pre-treatment of the substrate is critical for the adhesion of the polymerized coatings. This confirms that the polymerization is initiated from radicals grafted on the surface of the substrate by the DBD treatment with subsequent interlocking with the substrate by covalent bonds as well as cross-linking in the volume of the polymerized coating. 
For poly-ether coatings as well, the resistance to washing has been evidenced by surface FTIR-ATR, XPS and SEM analysis. Preliminary tests have been performed on coated PE and PS samples dipped in distilled water from 2 to 12 hours. The surface roughness has been used to evidence from SEM pictures that the ether coatings on PE were resistant to washing in water. Besides, the absorbance bands specific to ether $\left(1066\right.$ and $\left.1126 \mathrm{~cm}^{-1}\right)$ decrease by $20 \%$ after $2 \mathrm{~h}$ washing and then level off to a stable value with washing time. XPS analysis have shown an incomplete recovery of the $\% \pi-\pi^{*}(291.5 \mathrm{eV})$ of the initial untreated reference PS upon washing related to a residual polymerized ether coating of a few nm. However, this also shows an important loss of ether functions. This is probably due to the release of residual monomer trapped in the polymer net, of homo-polymer not grafted on the surface and of polymerized monomer on delaminated slices of oxidized PS. Besides, with softer DBD treatments preventing the delamination of the PS substrate, better resistance to washing have been recorded. Our results highlight a good adhesion of the so-formed poly-acid and polyether coatings related to covalent interlocking with both PE and PS substrates pre-treated by DBD. However, the poor cross linking in the volume of the poly-ether coating on PS would have to be increased for instance by UV irradiation during polymerization.

\section{4- Conclusion}

Functional, homogeneous and dense (no pores) polymer coatings, resistant to washing, can be achieved at atmospheric pressure with controlled thickness at significant deposition rates of a few hundred nanometers per second. Indeed, poly-acid and poly-ether functional coatings can be grafted in air at atmospheric pressure by post-DBD polymerization of liquid vinyl monomer, such as acrylic acid on PE and mono-vinyl ether on PE and PS substrates. Hence, we have proved the feasibility of this non-thermal plasma process for functional thin film deposition at atmospheric pressure. This process would deserve to be developed for industrial exploitation, all the more that the initial patent ${ }^{[15]}$ is not maintained anymore. 
A special attention is paid to the modifications of polymer films due to the initial surface treatment by micro-discharges induced in filamentary air DBD. Results have been discussed in terms of power density to deal with the dynamic of substrate heating by DBD and cooling by heat exchanges to define the range of power density preventing from thermal deformation of the polymer substrate. Both the energy per micro-discharge and the power density are shown to be critical to prevent from thermal film deformation and to achieve homogeneous surface properties at a millimeter scale despite homogeneously distributed sub-micrometer craters formed by the micro-discharges interaction with the polymer surface.

On the contrary, when dealing with the post-discharge surface density of species triggering the polymerization, the energy density deposited during the DBD treatment is used to compare chemical effects of different DBD pre-treatments. Indeed, the energy density is a time integrated value which accounts for cumulative effect of successive micro-discharges and for the related final active species densities on the polymer film substrate to be coated. Then, the observed saturation of the polymerization yield versus the energy density is probably related to the self-consumption of active species for higher energy densities. The post-discharge polymerization mechanism has been depicted with respect to polymerization yield evolution with DBD treatment and ES deposition parameters.

At first, the retention of both monomer functionalities (acid and ether) implies that polymerization is initiated by the vinyl group of the precursor keeping the functionality of the monomer in the final polymerized coating, whatever the deposited mass of liquid monomer is.

Besides, the final mass of such polymerized functional coating per surface unit depends on the energy density deposited by the initial DBD treatment, on the time of exposure to air between DBD treatment and monomer deposition and on the mass of liquid monomer deposited per surface unit. We have shown that the polymerization yields increase with surface density of active species triggering the polymerization of vinyl precursors from the surface leading to the adhesion of plasma polymerized layers on the PE and PS substrates. 
The surface density of active sites is shown to depend on the energy density of the DBD treatment and on the time exposure to air before deposition of the monomer. This is probably related to the evolution of the surface density of radicals and other peroxides and hydroperoxides. Indeed, surface density of radicals decreases within seconds after the discharge treatment when exposed to air through reactions with oxygen and surface recombination of oxygenated radicals into peroxides, as shown by the evolution of the related polymerization yield versus the transit time with air exposure before liquid monomer deposition. Then, the density of active sites triggering the polymerization remains constant for exposure to air of a few hundred seconds probably due to delayed production of surface radicals from peroxide dissociation. For air exposure longer than an hour before deposition, the yield decreases to 2$3 \%$ probably related to homo-polymerization in volume forming non-adherent polymer without covalent binding to the substrate.

At last, the tests of resistance to washing confirm that the polymerization is initiated from radicals grafted on the surface of the substrate by the DBD treatment with subsequent interlocking with the substrate by covalent bonds as well as cross-linking in the volume of the polymerized acid and ether coatings on PE pre-treated by DBD. However, the cross linking within these polymer coatings still deserves to be investigated when post-discharge polymerization occurs under UV irradiation and improved for poly-ether coatings on PS.

Acknowledgements: The authors wish to thank Pr. D. Mantovani and his team of Laval University Québec, Canada, for XPS analyses and critical discussions.

Received: ((will be filled in by the editorial staff)); Revised: ((will be filled in by the editorial staff)); Published online: ((will be filled in by the editorial staff));

DOI: ((will be filled in by the editorial staff)) 
Keywords: adhesion, coatings, dielectric barrier discharges (DBD), downstream plasma functionalization of polymers, plasma-initiated polymerization (of liquid)

[1] F. Denes, Trends Polym. Sci., 1997, 5, 23.

[2] J. Wu, R.B. Timmons, J.S. Jen, F.E. Molock, Colloids and Surfaces B: Biointerfaces, 2000, 18, 235-248

[3] B. Gupta, J. G. Hilborn, I. Bisson, P. Frey, J. Applied Polymer Science, 2001, 81, 2993

[4] J. Thome, A. Holländer, W. Jaeger, I. Trick, C. Oehr, Surface and Coatings Technology, 2003, 584, 174

[5] V. Castelvetro, E. Fatarella, L. Corsi, G. Ciardelli, Plasma Proc. \& Polym., 2006, 3, 48 [6] M. Tatoulian, F. Arefi-Khonsari, L. Tatoulian, J. Amouroux, J.-P. Borra, Chem. Mater., 2006, $18,5860-5863$

[7] M.Tatoulian, F Arefi-Khonsari, J-P Borra, Plasma Process. and Polym., 2007, 4, 360-369

[8] J. Petersen, R. Bechara, J. Bardon, T. Fouquet, F. Ziarelli, L. Daheron, V. Ball, V.

Toniazzo, M. Michel, A. Dinia, D. Ruch, Plasma Process. And Polym. 2011, 8, 895-903

[9] G. Da Ponte, E. Sardella, F. Fanelli, A. Van Hoeck, R. d'Agostino, S. Paulussen, P. Favia Surface \& Coatings Technology 2011, 205, S525-S528

[10] F. Massines, P. Segur, N. Gherardi, C. Khamphan, A. Ricard, Surf. Coating Tech. 2003, $174-175,8$.

[11] L. Dani, G. Mader, P. Grabau, B. Dresler, D. Linaschke,E. Lopez, S. Kaskel, E. Beyer, Contrib. Plasma Phys. 2009, 49,662;

[12] L.J Ward, W. Scofield, J. Badyal, A. Goodwin, J. Chem. Mater., 2003,15, 1466

[13] L. J. Ward, W. Scofield, J. Badyal, A. Goodwin, P. Merlin, Langmuir, 2003, 19, 2110

[14] P. A. F.Herbert, L. O'Neill, J. Wolińska, C. P.Stallard, A. Ramamoorthy, and D. P. Dowling, (2011), Plasma Process. And Polym. 2011, 8, 230-238

[15] Fr., 0407084 - (2004), CNRS, JP Borra, M. Tatoulian, F. Arefi-Khonsari, Chem Abstr. 
[16] M. Petit, N. Jidenko, A. Goldman, M. Goldman, J.-P. Borra. Review of Scientific Instruments, 2002, 73, 2705-2712

[17] N. Jidenko, M. Petit, J-P. Borra. J. Physics D-Applied Physics, 2006, 39, 281-293

[18] J. H. Scofield, J. Electron Spectrosc. 1976, 8, 129.

[19] Z Fang, X Xie, J Li, H Yang, Y Qiu and E Kuffel J. Phys.D:Appl.Phys. 2009, 42, 85204 [20] N Jidenko and JP Borra J. Phys. D: Appl. Phys. 2010, 43295203

[21] JP Borra, J. Phys. D: Appl. Phys., 2006, 39, R19-R54

[22] JP Borra, N. Jidenko N, C. Dutouquet C, O. Aguerre O., J. Hou J., A. Weber., Eur. Phys. J. Appl. Phys., 2011, 56-2, topical issue from "18th Int. Coll. on Plasma Processes, 24019. [23] "Plastics additives handbook" ; edited by R. Gäther and H. Müller- 3rd editionMunich;Vienna;New York: Hanser, 1990 pp238 - 241

[24] "Diamond and Related Materials Research" Chapter 8, M.N. Nguyen, S. Amar Dahoumane, T.Matrab,C. Mangeney, JP Boudou, M. Chehimi, ISBN 978-1-60456-145-6, Editor: Shota Shimizu, Nova Science Publishers, Inc , Hauppauge, New York 2008.

[25] MR.Alexander, JD Whittle, D. Barton, RD. Short, J. Mater. Chem, 2004, 14, 408-412 [27] M. Kuzuya, S. I.Kondo, M.Sugito, T.Yamashiro Macromolecules, 1998,31, 3230-3234 [28] G. Zhao, Y. Chen, X. Wang, Applied Surface Science, 2007, 253, 4709-4714

[29] C. Wang, J.-R. Chen, Applied Surface Science, 2007, 253, 4599-4606

[30] K. Kato, E. Uchida, E.T. Kang, Y. Uyama, Y. Ikada, Progress in Polym. Sc., 2003, 28, 209-259

[31] “Electrostatic Spraying of Liquids” A. Bailey, Ed. J. Wiley \& Son Inc. Res. Studies Press Hoboken, New Jersey, 1988

[32] M. Cloupeau, B. Prunet-Foch, Journal of Electrostatics, 1990, 25, 165-190

[33] RPA Hartmann, JP Borra, D Brunner, JCM Marijnessen and B Scarlett, J. Electrostatics, 1999, 47, 143-170 
Jean-Pascal Borra completed the Master's degree in Chemistry and Industrial Process Engineering in 1991 and his PhD thesis in Physics and chemistry at Pierre and Marie Curie University in 1995, on "Electro-meteorological conditions of induction and contribution to atmospheric gaseous and aerosol budget of electrical point discharges from trees" under the direction of Professor Goldman.

As a post-doctorate in the Aerosol Technology Group of Professors B. Scarlett and J.CM. Marijnissen at TU Delft, Netherlands, he studied the Electro-Spray physics and developed a new process of micro-reactivity by bipolar mixing of charged droplets, in 1995. Back to France in 1996 to join the National Center for Scientific Research (CNRS) as a senior researcher, he developed aerosol processes for materials production and aerosol charging by atmospheric pressure plasmas in the Laboratory of Physics of Gases and Plasmas at Supélec (Ecole Supérieure d'Electricité) in Gif-sur-Yvette, close to Paris. He became the manager of the team "Electrical Discharges and Aerosols", in 2000 and taught aerosol and discharge physics and applications in different Universities. Based on controlled experimental conditions and calibrated electro-thermal characterization of corona, streamer and Dielectric Barrier Discharges as well as gaseous and aerosol products analysis, he has produced more than 30 scientific full papers and reviews, 70 international conferences and different patents. For his significant contribution to the development of aerosol science, he was distinguished by the international Smoluchovski award in 2006. Dr. Borra is involved in the French Association for Aerosol Research (ASFERA) to organize the annual French Aerosol Conference. His main contributions deal with aerosol electro-filtration, chargers for size distribution measurements and nano-materials production $\left(\mathrm{MoS}_{2}\right.$ nano-boxes, Metal, Oxides and Polymer coated nano-particles). Besides, he has proposed and contributed to develop the non-thermal plasma process for the production of highly functionalized thin films by postDBD electro-spraying of liquid monomer, presented here.

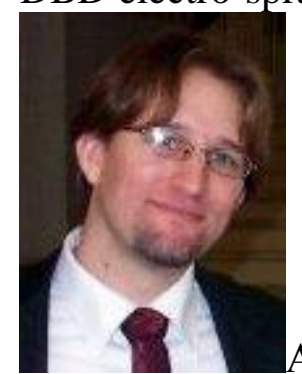

Alexandre Valt was born in 1981 near Paris, France. After the Master's degree in Industrial Process Engineering in 2004, he obtained the PhD degree with a thesis on Plasma Process Engineering at Pierre and Marie Curie University in 2008. His work treated on the study of two polymerization processes from a gaseous precursor in radiofrequency plasma at low pressure and from a liquid precursor deposited on an substrate activated by dielectric barrier discharge at atmospheric pressure in order to obtain thin polymeric layers. The study carried on the organic substrate functionalisation by ether functions, known for the anti-adhesive properties towards biological microorganisms. This work was conducted between the Laboratory of plasma processes and surface treatments engineering in Paris and the Laboratory of Physics of Gases and Plasmas at Supélec (Ecole Supérieure d'Electricité) in Gif-sur-Yvette. Since 2010, Dr. Valt works as consultant in financing innovation at Alma Consulting Group, in Lyon, France, to assist companies in obtaining government grants for their research. 
Mrs. Farzaneh AREFI-KHONSARI is currently a full Professor in Chemical Engineering at the University of Pierre \& Marie Curie (Paris, France) and the director of the PhD school of Chemical Engineering and Advanced Technology since September 2007. Working in Plasma Chemistry and Plasma Processing of Polymers and Plasma assisted CVD since 1981, she has 9 international patents, over 100 scientific publications and 65 invited talks in plasma and material related international conferences and journals. Her research group studies the plasma-surface interactions and has developed plasma reactors (RF, fluidized bed, Dielectric Barrier Discharges, Atmospheric Pressure Plasma Jets, etc.) for the surface treatment of polymers and plasma deposition of organic or inorganic thin films. Their results have given rise to technology transfers such as adhesion improvement of polymers to metals and other materials and to international collaborations.

She is on the editorial board of Plasmas Processes \& Polymers (since 2004) and Journal of Plasma Medicine (since 2010). She has been on the editorial board of Journal of Adhesion Science and Technology (1999-2005) and Plasmas and Polymers (1995-2003). She is one of the founding members of the International Society of Plasma Medicine in 2009. She has been member of the scientific and organizing committee of many International conferences on Plasmas $(1999,2001,2003), 2$ nd and $4^{\text {th }}$ International Conference on Plasma Medicine. She has been a member of the Plasma Science and Technique Division of the International Union of Vacuum Science Techniques and Applications 2001-2004. She has been elected for the board of directors of the Plasma Chemistry Society in the period 2003-2011. She has been nominated as a member of the organizing committee of the Gordon Research Conference 2006 and 2008. She has been nominated as a member of the Advisory Board of the Twelfth International Conference on Plasma Surface Engineering.

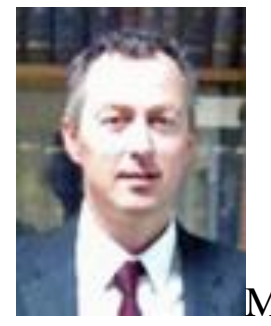

Michael Tatoulian received the Ph.D. degree in chemical engineering from Pierre et Marie Curie University (UPMC)-Paris 6 (Paris, France). He is now professor in the Laboratory of Plasma Processing and Surface Treatment (ENSCP, Paris, France) and the head of the research group "Plasma Processing, Materials and Microsystems' in the Chemical Engineering Department of ENSCP-Chimie ParisTech. He is the author of 103 scientific papers (46 in International refereed journals -57 in conference proceedings), 2 patents, 1 keynote, 1 plenary presentation and 21 invited talks, ( 9 in international conferences, 12 in laboratory or university seminars). His group is specialized in the surface modifications of a number of different materials (polymers, glass, steel...) by plasma technology. In particular, the "plasma team" has developed in the last ten years, lot of work in the plasma polymerization of organic and inorganic coatings, in low pressure or atmospheric pressure systems, enlarging the fields of applications of the plasma technology. In 2011, his group has been awarded by the "Ministere de la Recherche et de l'Enseignement Supérieure" in a call of proposal Equipex with the creation of a new institute named "Fondation Pierre Gilles de Gennes pour la microfluidique", aiming to develop applications of microfluidics and microreactors. In that context, a large part of the research work is dedicated to the development of catalytic microreactor and microfluidics systems dedicated to control of simple and double emulsions. 
Table 1: XPS analysis of PS before and after DBD treatment, showing the evolution of the Cls core level peak decomposition into five features(expressed in \%, as the ratio of the area for each Carbon bond over the total area of the Cls peak) and the Oxygen to Carbon ratio

\begin{tabular}{|c|c|c|c|c|c|}
\hline & \multirow{3}{*}{$\begin{array}{c}\text { Untreated } \\
\text { reference } \\
\text { PS }\end{array}$} & \multicolumn{4}{|c|}{ Post-DBD treatment } \\
\hline & & \multicolumn{3}{|c|}{$14 \mathrm{kV}$} & $16 \mathrm{kV}$ \\
\hline & & $\begin{array}{c}4.3 \mathrm{~mm} / \mathrm{s} \\
4 \mathrm{~J} / \mathrm{cm}^{2}\end{array}$ & $\begin{array}{l}3 \mathrm{~mm} / \mathrm{s} \\
6 \mathrm{~J} / \mathrm{cm}^{2}\end{array}$ & $\begin{array}{c}1 \mathrm{~mm} / \mathrm{s} \\
17 \mathrm{~J} / \mathrm{cm}^{2}\end{array}$ & $\begin{array}{l}4.3 \mathrm{~mm} / \mathrm{s} \\
60 \mathrm{~J} / \mathrm{cm}^{2}\end{array}$ \\
\hline$\% \mathrm{C}-\mathrm{C}(285 \mathrm{eV})$ & 89.5 & 83.2 & 83.8 & 82.4 & 77.0 \\
\hline \% C-O-C (286.5 eV) & 5.1 & 8.7 & 9.1 & 8.8 & 11.5 \\
\hline$\% \mathrm{C}=\mathrm{O}(288 \mathrm{eV})$ & 0.7 & 2.5 & 2.3 & 2.8 & 4.3 \\
\hline$\% \mathrm{O}-\mathrm{C}=\mathrm{O}(289.3 \mathrm{eV})$ & 0.6 & 2.3 & 2.0 & 2.8 & 3.7 \\
\hline$\% \pi-\pi^{*}(291.5 \mathrm{eV})$ & 4.1 & 3.3 & 2.8 & 3.2 & 3.5 \\
\hline$\% \mathrm{O} / \mathrm{C}$ & 5,8 & 14,4 & 15,5 & 17,0 & 20,9 \\
\hline
\end{tabular}


Supporting Information for Manuscript ppap.201100210

\section{Polymer surface patterning by DBD and post-discharge polymerization mechanism}

\section{J.-P. BORRA, A. VALT, F. AREFI-KHONSARI, M. TATOULIAN}

We present a route for grafting dense poly-acid and poly-ether coatings on polymers by postdischarge polymerization of liquid monomer. Surface modifications of polymer films due to the initial treatment by micro-discharges in air DBD (sub- $\mu \mathrm{m}$ craters and homogeneous surface properties) and post-DBD polymerization mechanism of liquid vinyl monomer triggered by surface radicals are depicted.

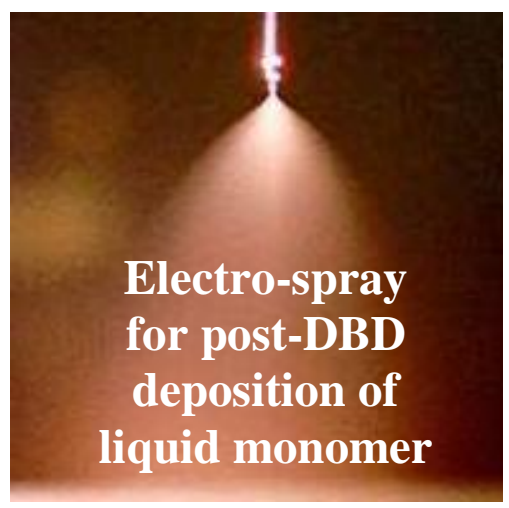

